\title{
Reinforcement of Natural Rubber with Core-Shell Structure Silica-Poly(Methyl Methacrylate) Nanoparticles
}

\author{
Qinghuang Wang, ${ }^{1}$ Yongyue Luo, ${ }^{2}$ Chunfang Feng, ${ }^{2,3}$ Zhifeng Yi, ${ }^{2,3}$ \\ Quanfang Qiu, ${ }^{2}$ L. X. Kong, ${ }^{3}$ and Zheng Peng ${ }^{2}$ \\ ${ }^{1}$ State Engineering and Technology Research Center for Key Tropical Crops, Haikou 571101, China \\ ${ }^{2}$ Chinese Agricultural Ministry Key Laboratory of Tropical Crop Product Processing, Agricultural Product Processing Research Institute, \\ Chinese Academy of Tropical Agricultural Sciences, Zhanjiang 524001, China \\ ${ }^{3}$ Centre for Material and Fiber Innovation, Institute for Technology Research Innovation, Deakin University, Geelong, \\ VIC 3217, Australia
}

Correspondence should be addressed to L.X. Kong, lingxue.kong@deakin.edu.au and Zheng Peng, zhengpeng8@yahoo.com

Received 18 March 2011; Revised 10 June 2011; Accepted 18 June 2011

Academic Editor: Aruna Ar Nanda

Copyright (C) 2012 Qinghuang Wang et al. This is an open access article distributed under the Creative Commons Attribution License, which permits unrestricted use, distribution, and reproduction in any medium, provided the original work is properly cited.

\begin{abstract}
A highly performing natural rubber/silica $\left(\mathrm{NR} / \mathrm{SiO}_{2}\right)$ nanocomposite with a $\mathrm{SiO}_{2}$ loading of $2 \mathrm{wt} \%$ was prepared by combining similar dissolve mutually theory with latex compounding techniques. Before polymerization, double bonds were introduced onto the surface of the $\mathrm{SiO}_{2}$ particles with the silane-coupling agent. The core-shell structure silica-poly(methyl methacrylate), $\mathrm{SiO}_{2}-$ PMMA, nanoparticles were formed by grafting polymerization of MMA on the surface of the modified $\mathrm{SiO}_{2}$ particles via in situ emulsion, and then $\mathrm{NR} / \mathrm{SiO}_{2}$ nanocomposite was prepared by blending $\mathrm{SiO}_{2}-\mathrm{PMMA}$ and PMMA-modified NR (NR-PMMA). The Fourier transform infrared spectroscopy results show that PMMA has been successfully introduced onto the surface of $\mathrm{SiO}_{2}$, which can be well dispersed in NR matrix and present good interfacial adhesion with NR phase. Compared with those of pure NR, the thermal resistance and tensile properties of $\mathrm{NR} / \mathrm{SiO}_{2}$ nanocomposite are significantly improved.
\end{abstract}

\section{Introduction}

Recently, considerable efforts have been expended on the preparation of organic/inorganic nanocomposite materials $[1,2]$. Inorganic nanoparticles possess small particle size, high surface area, as well as the quantum and surface effect, which make it possible for nanocomposites to perform more excellent physical and mechanical properties than conventional composites [3,4]. Multifarious nanoscale fillers, including calcium carbonate [5], montmorillonite [6], carbon black [7], and aluminum oxide [8], have been reported in academic journals. Among them, nanosilica $\left(\mathrm{SiO}_{2}\right)$, an important member of inorganic nanofiller in composites preparation, is widely used in the field of organic/inorganic hybrid composites. Zhu et al. [9] prepared well-dispersed silica-poly (methyl methacrylate) $\left(\mathrm{SiO}_{2}\right.$-PMMA) nanoparticles by a suspension-dispersion-polymerization technique in an aqueous system. Subsequently, $\mathrm{SiO}_{2}$-PMMA nanoparticles were induced into PVC matrix, and results showed that the heat resistance, elongation at break, and tensile strength of $\mathrm{PVC} / \mathrm{SiO}_{2}$ composites were significantly improved. Also, Peng et al. prepared natural rubber/silica nanocomposites $\left(\mathrm{NR} / \mathrm{SiO}_{2}\right)[10]$ and natural rubber/multiwalled carbon nanotubes composite [11] combining self-assembly and latexcompounding techniques. Obtained nanocomposites were perfectly strengthened, with increased thermal resistance and mechanical properties.

But on the other hand, as nanoscaled particles, nanosilica tend to the lowest energy state of bulk aggregation in polymer matrix because of large surface area and high surface energy, which in turn leads to structure flaws in the polymer matrix and interfere with the property of the whole product $[12,13]$. In order to enhance interfacial adhesion between nanosilica and NR matrix and improve the dispersion of nanoparticles 
in NR matrix, it is necessary to reinforce the compatibility between the organic matrix and the inorganic surface of nano-silica. Due to large numbers of hydroxy group on the surface of raw nanosilica $[14,15]$, its surface is easily compatible with polar polymers, such as PVA and PVC compared to the apolar matrix, natural rubber. According to traditional method, the most commonly used method to disperse nanosilica was the mixing process conducted in two-roll mill $[16,17]$. Despite well-distributed polymer composite can be finally obtained, the contamination of fly ash and the side effect on the lung of individuals are difficult to be avoided during the preparation of composite in either the laboratory or factory. Also, this method possesses some other advantages, such as low energy cost and homogeneous dispersion of silica in NR matrix. Latex compounding, therefore, can reduce harmful situation mentioned above, and be more eco-friendly and low-polluted processing. However, in order to obtain homogeneous dispersion of polar nanosilica in apolar natural rubber latex, surface modification of nanoparticles is required. There has been numerous numbers of publications reported in this field, such as chemical coating using coupling agents [18-21] and physical coating using detergents [22] whereas rare researches are referred to the surface functionalization of nanosilica and dispersing process in natural rubber latex. In this paper, a novel method to prepare $\mathrm{NR} / \mathrm{SiO}_{2}$ nanocomposite will be reported. Well-dispersed core-shell $\mathrm{SiO}_{2}$-PMMA nanoparticles were prepared by using MPS as bridge in aqueous solution. In addition, NR latex was modified by PMMA in emulsion system before mixing with core-shell nanoparticles via combining similar dissolve mutually theory and latex-compounding techniques. It is proved that this method is useful and core-shell $\mathrm{SiO}_{2}$-PMMA nanoparticles are rarely reported in NR latex application, and we will systematically discuss the synthesizing process and also investigate the relationship between microstructure and macroproperties.

\section{Experimental}

2.1. Materials. Natural rubber latex (NRL) with a total solid content of $60 \%$ was obtained from Qianjin state farm (Guangdong, China). Silica nanoparticles (average diameter: $7 \mathrm{~nm}$ ) were purchased from Sigma-Aldrich (Sigma-Aldrich, St. Louis, MO). Methyl methacrylate (MMA) and tertbutyl hydroperoxide were purchased from Sinopharm, Ltd. (Shanghai, China). 3-(trimethoxysilyl) propyl methacrylate (MPS) was brought from Guangzhou Chemical Reagent Co. (Guangdong, China). Potassium persulfate (KPS) and Tetraethylenepentamine were offered by Xilong Chemical Co. (Guangdong, China). All experiments were carried out with distilled water.

\subsection{Preparation of the $\mathrm{NR} / \mathrm{SiO}_{2}$ Nanocomposite}

2.2.1. Coupling Modification of Nanosilica. We modified the surface of $\mathrm{SiO}_{2}$ particles with MPS. Firstly, MPS was hydrolyzed in $95 \%$ ethanol solution for 2 hours. Then a fixed amount of $\mathrm{SiO}_{2}$ with $95 \%$ ethanol as solvent was treated with an ultrasonic vibrator for $15 \mathrm{~min}$. Finally, $\mathrm{SiO}_{2}$ dispersion was dropped into hydrolyzed MPS with mechanical stir at $25^{\circ} \mathrm{C}$ for 5 hours, and its $\mathrm{pH}$ was adjusted to 10 with triethylamine [23]. The $\mathrm{SiO}_{2}$ /MPS dispersion was centrifuged followed by rinsing with ethanol for 3 times and then with distilled with water for 2 times.

\subsubsection{Copolymerization of MMA on the Surface of Nanosilica.} The surface-functionalized $\mathrm{SiO}_{2}$ was dispersed in an aqueous system with MMA and sodium dodecyl sulfate (SDS) in order to obtain nano-silica colloid [24] which was mixed with an aqueous solution of initiator potassium persulfate (KPS), and then charged into a flask with mechanical stirring at $55^{\circ} \mathrm{C}$ for 5 hours. PMMA, as the shell, was grafted onto the surface of $\mathrm{SiO}_{2} / \mathrm{MPS}$ due to the reaction of the vinyl groups between $\mathrm{SiO}_{2}$ /MPS and MMA.

2.2.3. Modification of NRL. NRL was treated in an aqueous solution where MMA, oleic acid, and tert-butyl hydroperoxide were mixed accompanying gentle mechanical stir at room temperature for 2 hours. The colloid system was heated to $60^{\circ} \mathrm{C}$, before dropping an aqueous solution of activating agent (tetraethylenepentamine), and then cooled to room temperature, finally NR-PMMA latex was obtained [25].

2.2.4. Synthesis of Nanocomposite. The $\mathrm{SiO}_{2}$-PMMA aqueous dispersion was dropped into a certain amount of NR-PMMA latex with a total solid content of $30 \%$ and the mixture was stirred for 24 hours, which was then dried to obtain $\mathrm{NR} / \mathrm{SiO}_{2}$ nanocomposite films. The loading of silica is $2 \mathrm{wt} \%$ in NR matrix.

2.3. Characterization. A Perkin-Elmer Spectra GX-I FTIR spectroscopy (Perkin-Elmer, Fremont, CA) was used to investigate surface chemistry of $\mathrm{SiO}_{2}$ after modification with a resolution of $4 \mathrm{~cm}^{-1}$ in the transmission mode. The liquid $\mathrm{SiO}_{2}$ were dragged up by copper network for transmission electron microscopy (TEM), and then were observed on a JEM-100CXII instrument (JEOL, Peabody, MA) with an accelerating voltage of $100 \mathrm{kV}$. The morphology of the nanocomposites was taken with a scanning electron micrographs (SEM), Philips XL30-EDAX instrument (Philips, Eindhoven, Netherlands), at an acceleration voltage of $10 \mathrm{kV}$. The cross-section of the samples was obtained by splitting bulk sample with liquid nitrogen treatment.

The dynamic-mechanical thermal analysis (DMTA) spectra were taken on rectangular specimens $(20 \times 4 \times$ $0.1 \mathrm{~mm}$ ) in tensile mode at a frequency of $5 \mathrm{~Hz}$ using a NETZSCH DMA 242C instrument (Germany), ranged from the temperature of $-120^{\circ} \mathrm{C}$ to $50^{\circ} \mathrm{C}$. Thermal decomposition of samples was performed with a Perkin-Elmer TGA-7 thermogravimetric analyzer (TGA); (Perkin-Elmer, Fremont, CA). The measurement of the samples (ca. $10 \mathrm{mg}$ ) was carried out in nitrogen from $50^{\circ} \mathrm{C}$ to $600^{\circ} \mathrm{C}$ at a heating rate of $10^{\circ} \mathrm{C} / \mathrm{min}$. Tensile test experiments were conducted on the instrument in compression model with a cross-head speed of $500 \mathrm{~mm} / \mathrm{min}$, and the sample length was $75 \mathrm{~mm}$, the minimum width was $4 \mathrm{~mm}$, and the thickness was $2 \mathrm{~mm}$. 


\section{Results and Discussion}

3.1. Mechanism of Preparing $\mathrm{NR} / \mathrm{SiO}_{2}$ Nanocomposite Process. Figure 1 describes the scheme of the manufacturing process of $\mathrm{NR} / \mathrm{SiO}_{2}$ nanocomposite. There are three main steps in this process. The first step is to form core-shell $\mathrm{SiO}_{2}-\mathrm{PMMA}$ nanoparticles. The silane-coupling agent MPS are hydrolyzed to form silanol groups which condense with hydroxyl groups on the surface of silica to form a covalent bond. Because of the grafted MPS, unsaturated double bond $(\mathrm{C}=\mathrm{C})$ is introduced onto the surface of silica nanoparticles [26]. When the silane-coupling agent grafted on the surface of $\mathrm{SiO}_{2}$ counters an unsaturated functional group in MMA, the copolymerization between $\mathrm{SiO}_{2}$ /MPS and the copolymer PMMA will take place if there is an appropriate initiator. Eventually the core-shell $\mathrm{SiO}_{2}$-PMMA nanoparticles are successfully obtained.

The second process is to prepare NR-PMMA latex. The modification mechanism is as follows [27].
(1) The initiators decompose to generate free radical:

$$
\mathrm{R} \longrightarrow \mathrm{R} \cdot
$$

(2) MMA monomers are initiated to polymerize by free radical $\mathrm{R} \bullet$.<smiles>[R]C([CH])(C)C(=O)OC</smiles>

MMA •

PMMA •

(3) PMMA chain growth process is accompanied with the radical transferring to NR macromolecule.

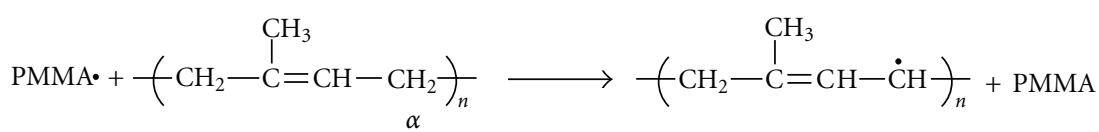

(4) The combination of two radicals terminates the entire reaction.

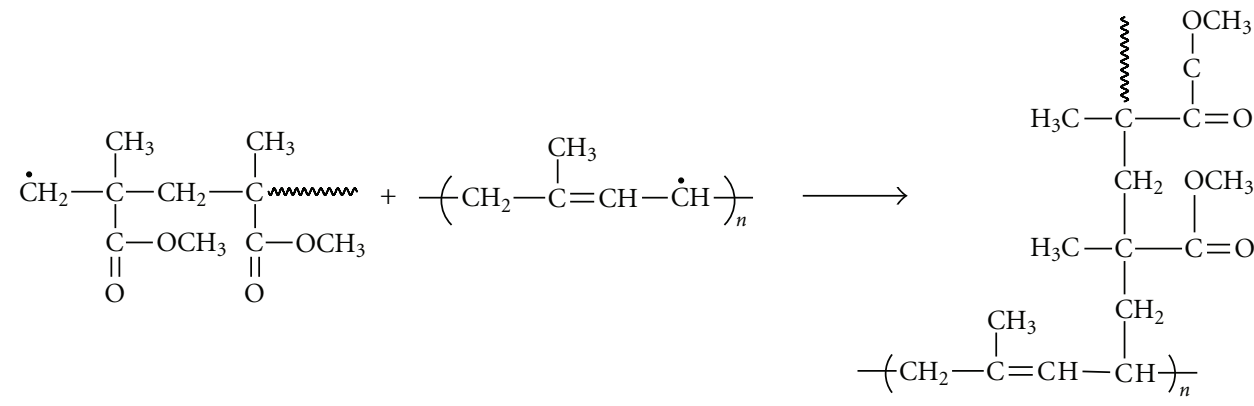

The last stage is to blend core-shell $\mathrm{SiO}_{2}$-PMMA nanoparticles and NR-PMMA via similar dissolve mutually theory. Compared with the other techniques $[28,29]$, the above-mentioned process is more convenient and effective in preparing $\mathrm{NR} / \mathrm{SiO}_{2}$ nanocomposite.

\subsection{Characterization of Core-Shell $\mathrm{SiO}_{2}-\mathrm{PMMA}$ Nanoparticles}

3.2.1. FTIR Study. After the formation of core-shell $\mathrm{SiO}_{2}-$ PMMA nanoparticles, either chemical reaction or physical adsorption would be characterized in the FTIR spectra. Therefore, before the measurement of FTIR, all the $\mathrm{SiO}_{2}$ nanoparticles modified with MMA have been extracted in acetone solution for 72 hours in order to eliminate ungrafted PMMA.

Figure 2 displays the infrared spectra of the eluate and pure acetone solution. It can be seen that the peak at $1730 \mathrm{~cm}^{-1}$ (Figure 2(A)) is assigned to $\mathrm{C}=\mathrm{O}$ stretching vibration of PMMA while after 72 hours extracting, this peak disappears and only $\mathrm{C}=\mathrm{O}$ stretching vibration of acetone at $1715 \mathrm{~cm}^{-1}$ could be seen (Figure 2(B)). It can be proved that after 72 hours extracting, there is no redundant PMMA absorbed physically on $\mathrm{SiO}_{2}$-PMMA nanoparticles. Subsequently, rinsed solid $\mathrm{SiO}_{2}$-PMMA and unmodified $\mathrm{SiO}_{2}$ were measured through FTIR. It can be seen from 


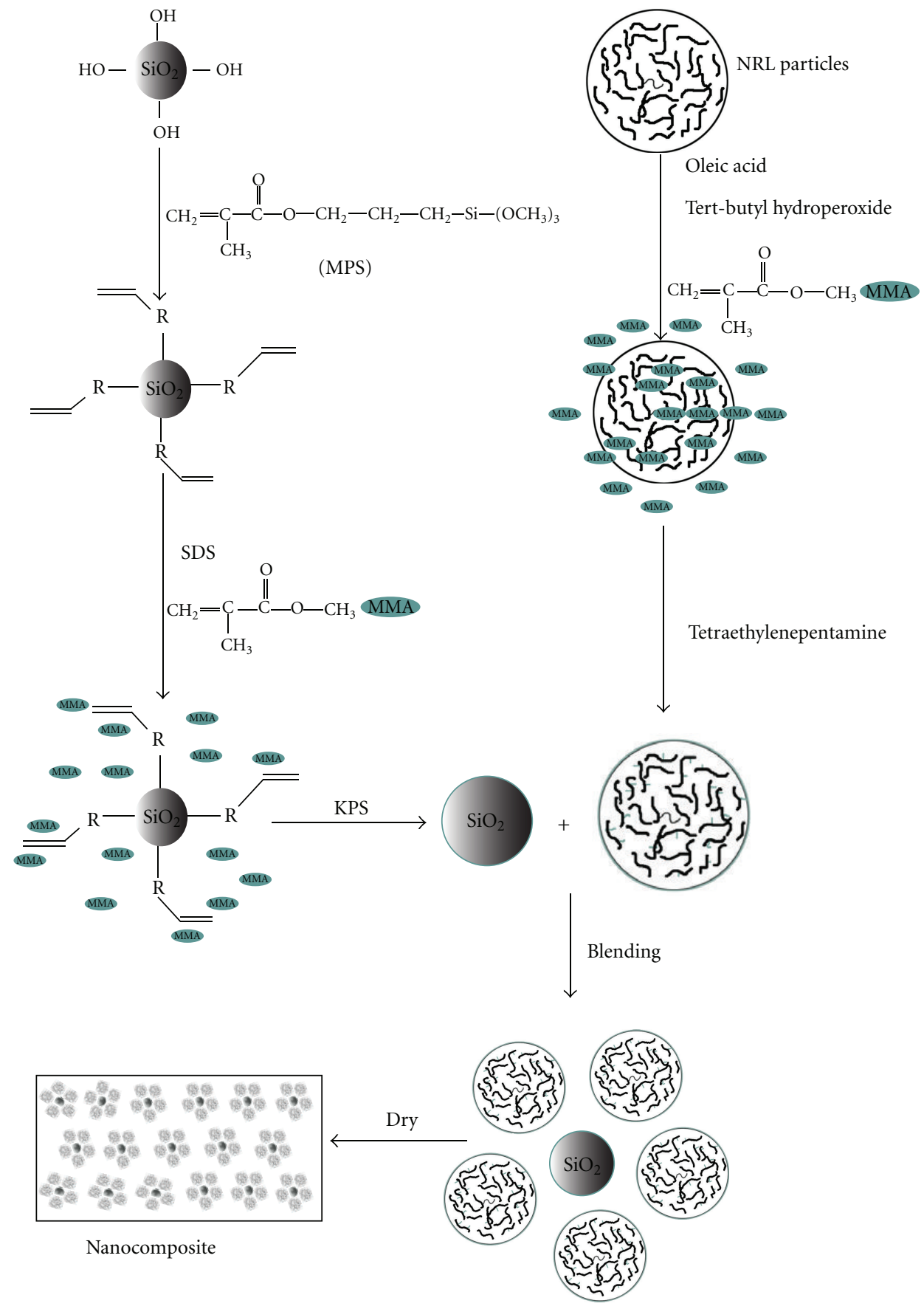

FIgURE 1: Manufacturing process of $\mathrm{NR} / \mathrm{SiO}_{2}$ nanocomposite.

Figure 3 that the adsorption peak at $1697 \mathrm{~cm}^{-1}$ assigned to the $\mathrm{C}=\mathrm{O}$ functional groups (Figure $3(\mathrm{~B})$ ) does not appear in Figure 3(A), which indicates that MPS has been successfully grafted on the surface of $\mathrm{SiO}_{2}$ [30] and $\mathrm{SiO}_{2}$ and MPS are linked with covalent bonds. Therefore, it is possible for MMA to graft onto the modified $\mathrm{SiO}_{2}$ nanoparticles. As can be seen from Figure $3(\mathrm{C})$ that the absorption peak at $1730 \mathrm{~cm}^{-1}$ assigned to the vibration absorption of $\mathrm{C}=\mathrm{O}$ is obvious, accompanying with one less pronounced peak at $2975 \mathrm{~cm}^{-1}$ corresponding to $\mathrm{CH}_{3}$ groups of PMMA. All the results obtained from FTIR spectra confirm that PMMA successfully grafted onto the $\mathrm{SiO}_{2}$ modified by MPS through chemical bonds rather than simply physical adsorption.

3.2.2. TEM Observation. It is obvious that unmodified $\mathrm{SiO}_{2}$ nanoparticles are aggregated together and the diameter ranges from $10 \mathrm{~nm}$ to $30 \mathrm{~nm}$ (Figure 4(a)) whilst because of the introduction of PMMA, nanoparticles $\left(\mathrm{SiO}_{2} / \mathrm{MMA}\right.$ $=1: 0.3$ ) indicate well-dispersed morphology (Figure 4(b)). However, after being grafted by PMMA, dispersibility of $\mathrm{SiO}_{2}$ is improved (Figure 4(b)). It can be also seen from Figure 4 (b) that single nanoparticle with a diameter around 


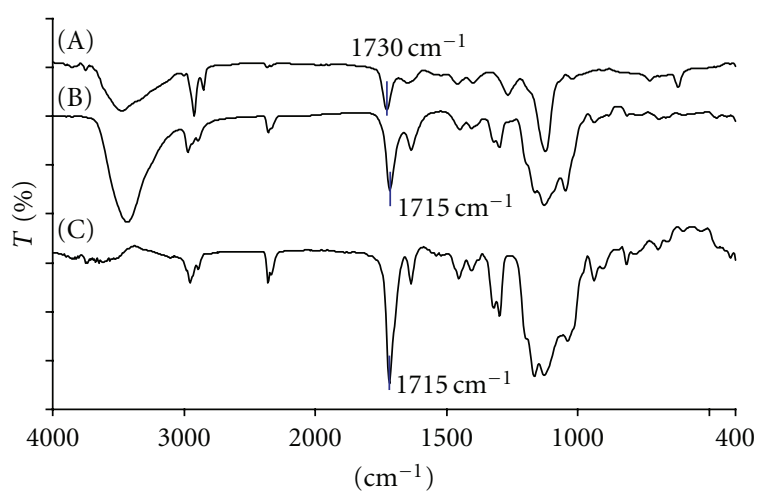

Figure 2: Infrared spectra of $\mathrm{SiO}_{2}$-PMMA soxhlet extraction solution. (A) The first eluate; (B) the second eluate; (C) pure acetone solution.

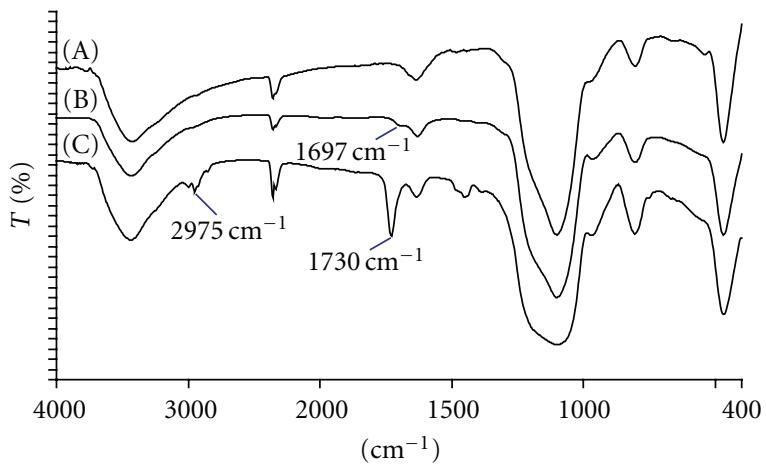

Figure 3: Infrared spectra of nanosilica, (A) unmodified $\mathrm{SiO}_{2}$; (B) $\mathrm{SiO}_{2}$-MPS; (C) $\mathrm{SiO}_{2}$-PMMA.

$40-60 \mathrm{~nm}$ can be clearly observed, which is $30 \mathrm{~nm}$ thicker than unmodified $\mathrm{SiO}_{2}$ particles. This illuminates that the core, $\mathrm{SiO}_{2}$ nanoparticles, is successfully coated by the shell, PMMA, and the thickness of PMMA shell is about 25$35 \mathrm{~nm}$. It can also be observed in the SEM images (Figure 5) where the core-shell $\mathrm{SiO}_{2}$-PMMA nanoparticles are evenly dispersed throughout NR matrix. However, when the ratio of $\mathrm{SiO}_{2} / \mathrm{MMA}$ reaches to $1: 3$, the sphere morphology is out of order (Figure 4(c)) due to the increasing prevalence of PMMA homopolymerization, and PMMA will physically be absorbed on the surface of nanosilica. Meanwhile, the aggregation of nano- $\mathrm{SiO}_{2}$ deteriorates, and the diameter of the $\mathrm{SiO}_{2}$ clusters becomes much bigger compared with Figure 4(b). Therefore, from the results above the suitable $\mathrm{SiO}_{2} / \mathrm{MMA}$ ratio is $1: 0.3$, which is proved to be the proper grafting rate through large amounts of experimental work.

\subsection{Characterization of $\mathrm{NR} / \mathrm{SiO}_{2}$ Nanocomposites}

3.3.1. SEM Observation. In recent work, $\mathrm{NR} / \mathrm{SiO}_{2}$ nanocomposite was prepared with a constant mixture rate $\left(\mathrm{NR} / \mathrm{SiO}_{2}=\right.$ 98/2). Because $\mathrm{SiO}_{2}$ has been surface-functioned with MPS and MMA, the compatibility is improved between $\mathrm{SiO}_{2}$ nanoparticles and NR matrix, and, moreover, $\mathrm{SiO}_{2}-\mathrm{PMMA}$ nanoparticles with an average size ranged from $60 \mathrm{~nm}$ to
$100 \mathrm{~nm}$ are uniformly dispersed in the matrix as individual spherical core-shell structure (Figure 5(c)). Whereas unmodified $\mathrm{SiO}_{2}$ in NR matrix (Figures 5(a) and 5(b)) aggregate significantly and the size of the $\mathrm{SiO}_{2}$ clusters reaches to more than $200 \mathrm{~nm}$. These results illustrate that the excellent compatibility between the $\mathrm{SiO}_{2}$-PMMA and NR-PMMA enhances the interaction between $\mathrm{SiO}_{2}$ and $\mathrm{NR}$, and thus improves the adhesion and morphological structure of $\mathrm{NR} / \mathrm{SiO}_{2}$ nanocomposites. The preparation method of polymer $/ \mathrm{SiO}_{2}$ composites has been widely reported, such as melt compounding [31] and other physical blending [32], however, the process presented in this paper possesses significant advantages, for instance, the compatibility with $\mathrm{NR}$ is excellent and the size of $\mathrm{SiO}_{2}$ is approximately $80 \mathrm{~nm}$.

3.3.2. Dynamic Thermal Mechanical Analysis. Dynamic thermal mechanical analysis (DTMA) can characterize the reaction between polymer molecular chains and inorganic particles and the transformation from glass state to viscoelastic state. It can be seen from Figure 6 that peaks of curves move to the direction of high temperature with the enhancement of compatibility which can be seen from SEM images (Figure 5). The glass-transition temperature $\left(T_{g}\right)$ can be calculated from the peak of tand-T curve. $T_{g}$ of NR-PMMA/SiO 2 -PMMA is obviously higher than that of the others (Figure 6), which reaches to $-48^{\circ} \mathrm{C}$. It could be attributed to the well-dispersed core-shell $\mathrm{SiO}_{2}$ PMMA nanoparticles in NR-PMMA matrix. PMMA play an important role in the molecular interaction between $\mathrm{SiO}_{2}$ and NR chains, declining the thermal motion of the NR molecule [33]. Therefore, the adapting temperature range of rubber products has been expanded with the loading of $2 \mathrm{wt} \%$ core-shell $\mathrm{SiO}_{2}$-PMMA nanoparticles.

In addition, NR-PMMA composite filled with core-shell $\mathrm{SiO}_{2}$-PMMA nanoparticles has a higher storage modulus than the others at the temperature ranged from $-100^{\circ} \mathrm{C}$ to $-50^{\circ} \mathrm{C}$ (Figure 7). When the temperature is below $T_{g}$, the core-shell $\mathrm{SiO}_{2}$-PMMA nanocomposites possess a high storage modulus, which is caused by introducing rigid nanosilica particles [34]. The increasing storage modulus attributes to the friction between the core-shell $\mathrm{SiO}_{2}$ PMMA nanoparticles and the NR-PMMA molecules when the nanosilica particles are thoroughly dispersed in the NR matrix.

3.3.3. The Thermal Gravimetric Analysis. All samples are measured in nitrogen environment, which means no oxygenolysis of polymer molecules and that it well proves the effect of the bridge molecule, PMMA. Adding $\mathrm{SiO}_{2}-$ PMMA nanoparticles can enhance the thermal stability of composites. The main thermal decomposition of NR matrix is at about $360^{\circ} \mathrm{C}$ (Figure 8) where $\mathrm{C}-\mathrm{C}$ chain bonds ruptured and hydrogen transferred [35]. The degradation curve of $\mathrm{NR}-\mathrm{PMMA} / \mathrm{SiO}_{2}$-PMMA is slightly shifted to a higher temperature, compared with the other samples, due to the intertwining between one PMMA chain on the surface of nanosilica and another PMMA chain grafted on NR molecules. 


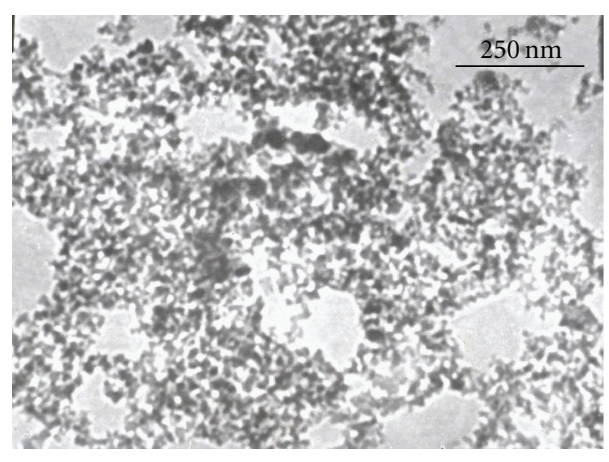

(a)

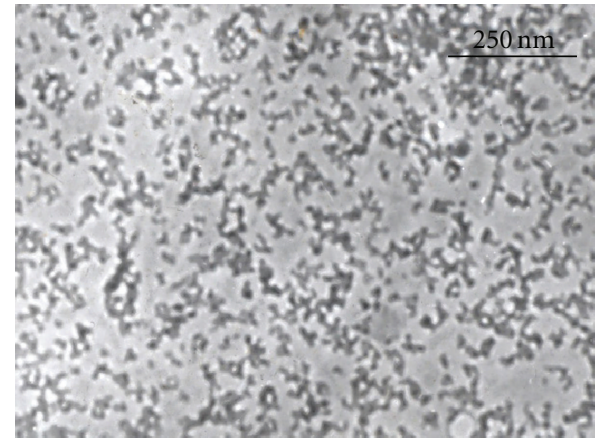

(b)

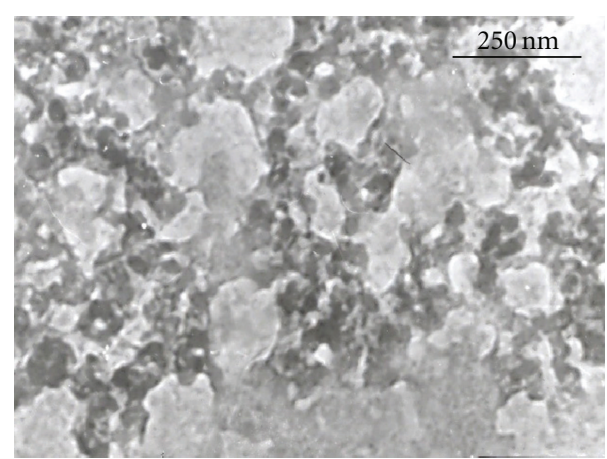

(c)

Figure 4: TEM micrographs of $\mathrm{SiO}_{2}$ nanoparticles in water. (a) Unmodified $\mathrm{SiO}_{2}$; (b) $\mathrm{SiO}_{2}-\mathrm{PMMA}\left(\mathrm{SiO}{ }_{2}: \mathrm{MMA}=1: 0.3\right.$ ); (c) $\mathrm{SiO}{ }_{2}-\mathrm{PMMA}$ $\left(\mathrm{SiO}_{2}: \mathrm{MMA}=1: 3\right)$

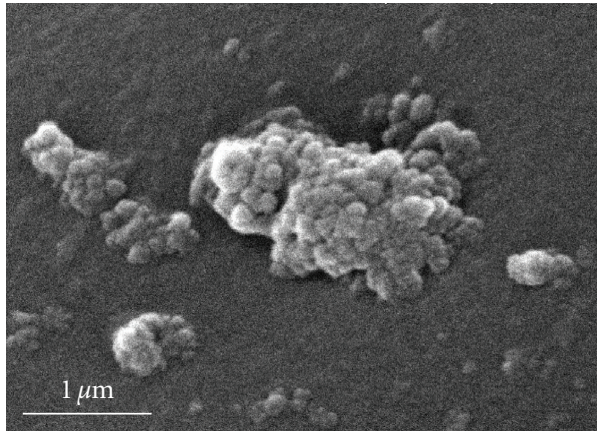

(a)

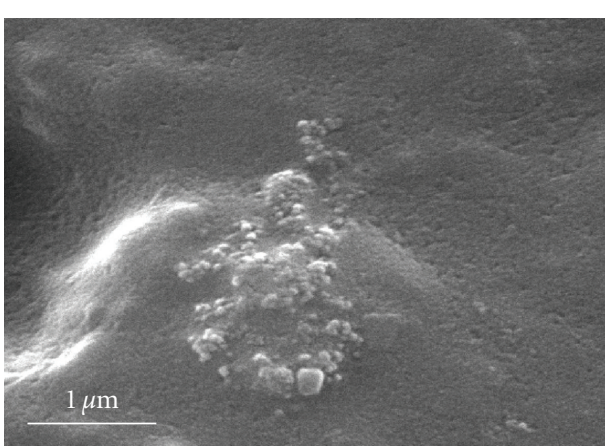

(b)

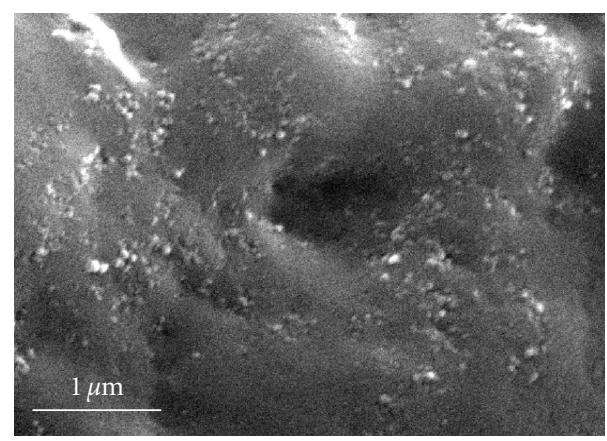

(c)

Figure 5: SEM micrographs of nanocomposites. (a) NR/SiO 2 ; (b) NR-PMMA/SiO 2 ; (c) NR-PMMA/SiO 2 -PMMA. 
TABLE 1: Tensile properties of pure NR and its nanocomposites $\left(\mathrm{SiO}_{2} / \mathrm{NR}=2 / 100 \mathrm{w} / \mathrm{w}\right)$.

\begin{tabular}{lcccc}
\hline Samples & NR & NR-PMMA & NR-PMMA/SiO & NR-PMMA/SiO \\
\hline Tensile strength/MPa & 6.99 & 7.23 & 8.95 & 10.65 \\
Elongation at break/\% & 835 & 823 & 772 & 773 \\
Tensile modulus/MPa & & & & 1.22 \\
300\% elongation & 0.92 & 0.82 & 1.46 & 1.95 \\
$500 \%$ elongation & 1.00 & 0.94 & 2.96 & 3.32 \\
$700 \%$ elongation & 1.58 & 2.06 & & \\
\hline
\end{tabular}

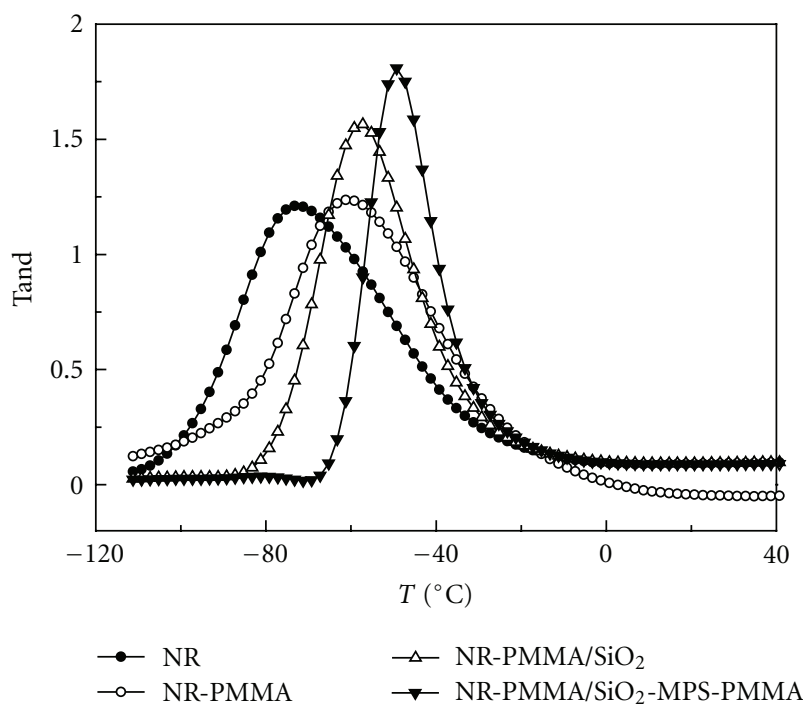

FIGURE 6: The loss factor as a function of temperature for pure NR and its nanocomposites.

During thermal decomposition, there are three main degraded temperatures, onset temperature $\left(T_{o}\right)$, peak temperature $\left(T_{p}\right)$, and flow temperature $\left(T_{f}\right)$. Those of the NR$\mathrm{PMMA} / \mathrm{SiO}_{2}$-PMMA nanocomposites increase by $5.4^{\circ} \mathrm{C}$, $4.9^{\circ} \mathrm{C}$ and $5.7^{\circ} \mathrm{C}$, respectively, in comparison with those of the pure NR. Incorporating with the distribution observed from SEM, the thermal stability depends on the distribution of $\mathrm{SiO}_{2}$ nanoparticles. The more homogenously the $\mathrm{SiO}_{2}$ nanoparticles disperse in NR matrix, the stronger the reaction between the molecules is [36]. Because the decomposition has been slowed down, the ageing resistance of nanocomposite is improved compared to the pure NR. This from another aspect supports the feasibility and efficiency of similar dissolve mutually theory in the preparation of $\mathrm{NR} /$ silica composite.

3.3.4. Tensile Property. The tensile performance has been investigated in detail among different samples, namely, NR, NR/PMMA, NR-PMMA/SiO ${ }_{2}$, and NR-PMMA/SiO ${ }_{2}-$ PMMA. Obviously, with the improvement of modification and the introduction of nanosilica, the tensile strength as well as tensile modulus at different elongations is increasingly high. It can be seen from Table 1 that the tensile strength increases by $3.66 \mathrm{MPa}$ from $6.99 \mathrm{MPa}$ (NR) to $10.65 \mathrm{MPa}$ (NR-PMMA/SiO 2 -PMMA). Since PMMA is grafted both on

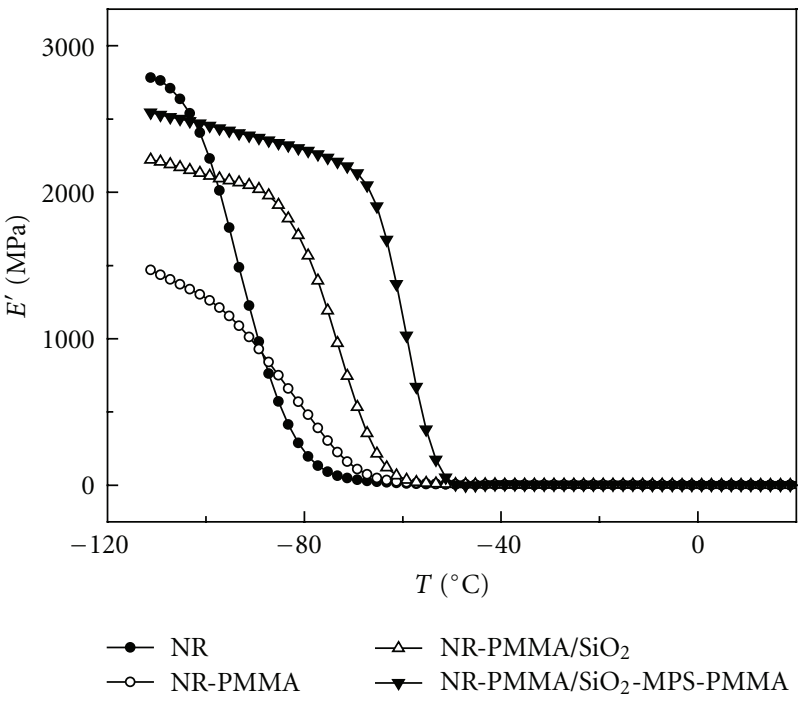

FIgure 7: The storage modulus as a function of temperature for pure NR and its nanocomposites.

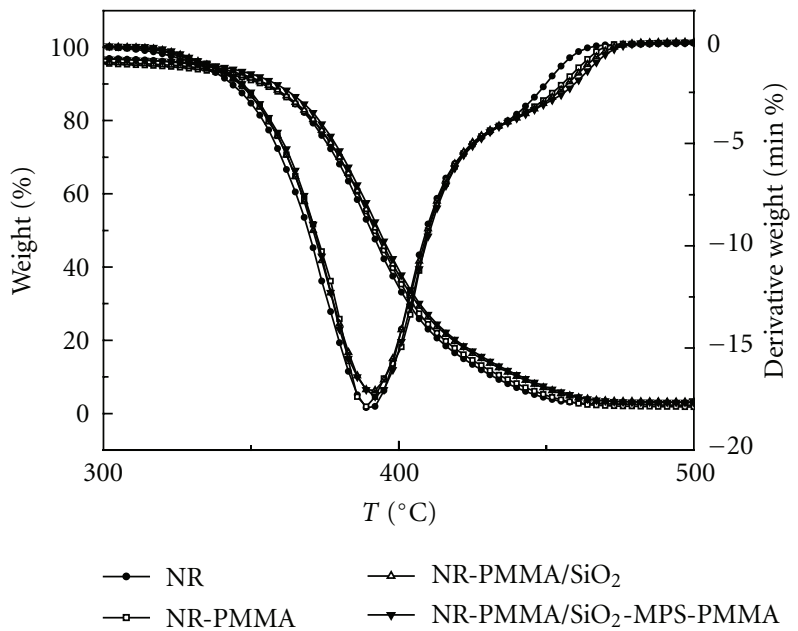

FIGURE 8: TG/DTG curves of pure NR and its nanocomposites in nitrogen.

$\mathrm{SiO}_{2}$ and $\mathrm{NR}$, its molecule chains twist together via similar dissolve mutually theory, reinforcing the interaction between nano- $\mathrm{SiO}_{2}$ and $\mathrm{NR}$ matrix and hindering the movement of NR macromolecule chains [37]. That is to say that PMMA as a bridge between the inorganic nanoparticles and 
polymer matrix improve the mutual compatibility which in turn results in excellent mechanical property. In addition, comparing the tensile strength between NR-PMMA and NR-PMMA/SiO 2 , nanosilica without grafting PMMA on its surface can also reinforce the tensile property, from 7.23 to $8.95 \mathrm{MPa}$.

\section{Conclusion}

A novel methodology, similar dissolve mutually theory, is introduced to prepare $\mathrm{NR} / \mathrm{SiO}_{2}$ nanocomposite in this paper. The core-shell $\mathrm{SiO}_{2}$-PMMA particles ranged from $60 \mathrm{~nm}$ to $100 \mathrm{~nm}$ are well dispersed in latex at a suitable $\mathrm{SiO}_{2} / \mathrm{MMA}$ ratio of $1: 0.3$, and the thickness of PMMA shell is about 25$35 \mathrm{~nm}$. Moreover, the dispersion of core-shell $\mathrm{SiO}_{2}-\mathrm{PMMA}$ nanoparticles has been improved by grafting PMMA on both nano- $\mathrm{SiO}_{2}$ and $\mathrm{NR}$ molecule chains. Based on the excellent dispersion of $\mathrm{SiO}_{2}$-PMMA nanopaticles, $T_{g}$ and thermal ageing resistances of nanocomposite are considerably enhanced. Meanwhile, the tensile strength increases by $3.66 \mathrm{MPa}$ compared with the pure NR. The recent research is merely focusing on $2 \mathrm{wt} \%$ loading of nanosilica, and further work will be extended into different addition of nanosilica.

\section{Acknowledgments}

The financial support from the Natural Science Foundation of China (Contract Grant no. 50763006), Ministry of Science and Technology R \& D research institutes special fund (Contract Grant no. 2008EG134285) and 973 Program special fund (Contract Grant no. 2010CB635109) are gratefully acknowledged.

\section{References}

[1] L. Qi and S. J. Dong, "Organic/inorganic nanocomposite polymer electrolyte," Chinese Chemical Letters, vol. 18, no. 2, pp. 185-188, 2007.

[2] W. E. Mahmoud, "A novel photodiode made of hybrid organic/inorganic nanocomposite," Journal of Physics D, vol. 42, no. 15, Article ID 155502, 2009.

[3] J. P. Salvetat, S. Bhattacharyya, and R. B. Pipes, "Progress on mechanics of carbon nanotubes and derived materials," Journal of Nanoscience and Nanotechnology, vol. 6, no. 7, pp. 1857-1882, 2006.

[4] Y. Xie, C. A. S. Hill, Z. Xiao, H. Militz, and C. Mai, "Silane coupling agents used for natural fiber/polymer composites: a review," Composites Part A, vol. 41, no. 7, pp. 806-819, 2010.

[5] I. Kemal, A. Whittle, R. Burford, T. Vodenitcharova, and M. Hoffman, "Toughening of unmodified polyvinylchloride through the addition of nanoparticulate calcium carbonate," Polymer, vol. 50, no. 16, pp. 4066-4079, 2009.

[6] S. Habibi, A. Rashidi, S. Bazgir, A. A. Katbab, and M. Montazer, "Preparation and flame retardancy of poly(ethylene terephthalate)/ montmorillonite nanocomposites," Asian Journal of Chemistry, vol. 21, no. 6, pp. 4881-4888, 2009.

[7] C. Nakason, W. Pechurai, K. Sahakaro, and A. Kaesaman, "Rheological, thermal, and curing properties of natural rubber-g-poly(methyl methacrylate)," Journal of Applied Polymer Science, vol. 99, no. 4, pp. 1600-1614, 2006.
[8] K. Balani, S. P. Harimkar, A. Keshri, Y. Chen, N. B. Dahotre, and A. Agarwal, "Multiscale wear of plasma-sprayed carbonnanotube-reinforced aluminum oxide nanocomposite coating," Acta Materialia, vol. 56, no. 20, pp. 5984-5994, 2008.

[9] A. Zhu, Z. Shi, A. Cai, F. Zhao, and T. Liao, "Synthesis of coreshell PMMA- $\mathrm{SiO}_{2}$ nanoparticles with suspension-dispersionpolymerization in an aqueous system and its effect on mechanical properties of PVC composites," Polymer Testing, vol. 27, no. 5, pp. 540-547, 2008.

[10] Z. Peng, L. X. Kong, S. D. Li, Y. Chen, and M. F. Huang, "Selfassembled natural rubber/silica nanocomposites: its preparation and characterization," Composites Science and Technology, vol. 67, no. 15-16, pp. 3130-3139, 2007.

[11] Z. Peng, C. Feng, Y. Luo, Y. Li, and L. X. Kong, "Self-assembled natural rubber/multi-walled carbon nanotube composites using latex compounding techniques," Carbon, vol. 48, no. 15, pp. 4497-4503, 2010.

[12] C. Charitidis and S. Logothetidis, "Nanoscale effects on the nanomechanical properties of multifunctional materials," Computational Materials Science, vol. 33, no. 1-3, pp. 296-302, 2005.

[13] J. Oberdisse, "Aggregation of colloidal nanoparticles in polymer matrices," Soft Matter, vol. 2, no. 1, pp. 29-36, 2006.

[14] Z. Y. Shen, L. Y. Li, Y. Li, and C. C. Wang, "Fabrication of hydroxyl group modified monodispersed hybrid silica particles and the $\mathrm{h}-\mathrm{SiO}_{2} / \mathrm{TiO}_{2}$ core/shell microspheres as high performance photocatalyst for dye degradation," Journal of Colloid and Interface Science, vol. 354, no. 1, pp. 196-201, 2011.

[15] W. Xueqin, Z. Chunxi, J. Jing, S. Ningfang, and X. Hongjie, "Radiation-induced attenuation effect in hydroxyl-rich puresilica-core photonic crystal fiber," Optik. In press.

[16] S. Prasertsri and N. Rattanasom, "Mechanical and damping properties of silica/natural rubber composites prepared from latex system," Polymer Testing, vol. 30, no. 5, pp. 515-526, 2011.

[17] L. N. Carli, C. R. Roncato, A. Zanchet et al., "Characterization of natural rubber nanocomposites filled with organoclay as a substitute for silica obtained by the conventional two-roll mill method," Applied Clay Science, vol. 52, no. 1-2, pp. 56-61, 2011.

[18] J. P. Matinlinna, L. V. J. Lassila, and P. K. Vallittu, "The effect of five silane coupling agents on the bond strength of a luting cement to a silica-coated titanium," Dental Materials, vol. 23, no. 9, pp. 1173-1180, 2007.

[19] C. Cherkouk, L. Rebohle, W. Skorupa, T. Strache, H. Reuther, and M. Helm, "Spraying spin coating silanization at room temperature of $\mathrm{a} \mathrm{SiO}_{2}$ surface for silicon-based integrated light emitters," Journal of Colloid and Interface Science, vol. 337, no. 2, pp. 375-380, 2009.

[20] X. K. Ma, N. H. Lee, H. J. Oh et al., "Surface modification and characterization of highly dispersed silica nanoparticles by a cationic surfactant," Colloids and Surfaces A, vol. 358, no. 1-3, pp. 172-176, 2010.

[21] A. M. Kartal and C. Erkey, "Surface modification of silica aerogels by hexamethyldisilazane-carbon dioxide mixtures and their phase behavior," The Journal of Supercritical Fluids, vol. 53, no. 1-3, pp. 115-120, 2010.

[22] F. Ebihara and S. Watano, "Development of a novel granular detergent by inorganic solution binder," Journal of Chemical Engineering of Japan, vol. 35, no. 12, pp. 1263-1269, 2002.

[23] H. Yan, G. Tian, K. Sun, and Y. Zhang, "Effect of silane coupling agent on the polymer-filler interaction and mechanical properties of silica-filled NR," Journal of Polymer Science, Part $B$, vol. 43 , no. 5, pp. 573-584, 2005. 
[24] N. Sombatsompop, E. Wimolmala, and T. Markpin, "Fly-ash particles and precipitated silica as fillers in rubbers. II. Effects of silica content and Si69-treatment in natural rubber/styrenebutadiene rubber vulcanizates," Journal of Applied Polymer Science, vol. 104, no. 5, pp. 3396-3405, 2007.

[25] S. Ostad-Movahed, K. A. Yasin, A. Ansarifar, M. Song, and S. Hameed, "Comparing effects of silanized silica nanofiller on the crosslinking and mechanical properties of natural rubber and synthetic polyisoprene," Journal of Applied Polymer Science, vol. 109, no. 2, pp. 869-881, 2008.

[26] L. Bokobza and J. P. Chauvin, "Reinforcement of natural rubber: use of in situ generated silicas and nanofibres of sepiolite," Polymer, vol. 46, no. 12, pp. 4144-4151, 2005.

[27] L. Bokobza and O. Rapoport, "Silica and carbon black reinforcement of natural rubber," Macromolecular Symposia, vol. 194, no. 1, pp. 125-134, 2003.

[28] S. Varghese and J. Karger-Kocsis, "Natural rubber-based nanocomposites by latex compounding with layered silicates," Polymer, vol. 44, no. 17, pp. 4921-4927, 2003.

[29] R. Magaraphan, W. Thaijaroen, and R. Lim-Ochakun, "Structure and properties of natural rubber and modified montmorillonite nanocomposites," Rubber Chemistry and Technology, vol. 76, no. 2, pp. 406-418, 2003.

[30] R. Y. Hong, H. P. Fu, Y. J. Zhang et al., "Surface-modified silica nanoparticles for reinforcement of PMMA," Journal of Applied Polymer Science, vol. 105, no. 4, pp. 2176-2184, 2007.

[31] M. Tanahashi, M. Hirose, Y. Watanabe, J. C. Lee, and K. Takeda, "Silica/perfluoropolymer nanocomposites fabricated by direct melt-compounding: a novel method without surface modification on nano-silica," Journal of Nanoscience and Nanotechnology, vol. 7, no. 7, pp. 2433-2442, 2007.

[32] J. J. Chen, C. F. Zhu, H. T. Deng, Z. N. Qin, and Y. Q. Bai, "Preparation and characterization of the waterborne polyurethane modified with nanosilica," Journal of Polymer Research, vol. 16, no. 4, pp. 375-380, 2009.

[33] Z. Peng, L. X. Kong, and S. D. Li, "Dynamic mechanical analysis of polyvinylalcohol/silica nanocomposite," Synthetic Metals, vol. 152, no. 1-3, pp. 25-28, 2005.

[34] G. Sui, W. H. Zhong, X. P. Yang, Y. H. Yu, and S. H. Zhao, "Preparation and properties of natural rubber composites reinforced with pretreated carbon nanotubes," Polymers for Advanced Technologies, vol. 19, no. 11, pp. 1543-1549, 2008.

[35] Z. Peng and L. X. Kong, "A thermal degradation mechanism of polyvinyl alcohol/silica nanocomposites," Polymer Degradation and Stability, vol. 92, no. 6, pp. 1061-1071, 2007.

[36] R. Y. Hong, J. Z. Qian, and J. X. Cao, "Synthesis and characterization of PMMA grafted $\mathrm{ZnO}$ nanoparticles," Powder Technology, vol. 163, no. 3, pp. 160-168, 2006.

[37] R. Hong, T. Pan, and H. Fu, "On the silica/PMMA nanocomposites," Advanced Fibers and Polymer Materials, vol. 10, pp. 19-27, 2005. 

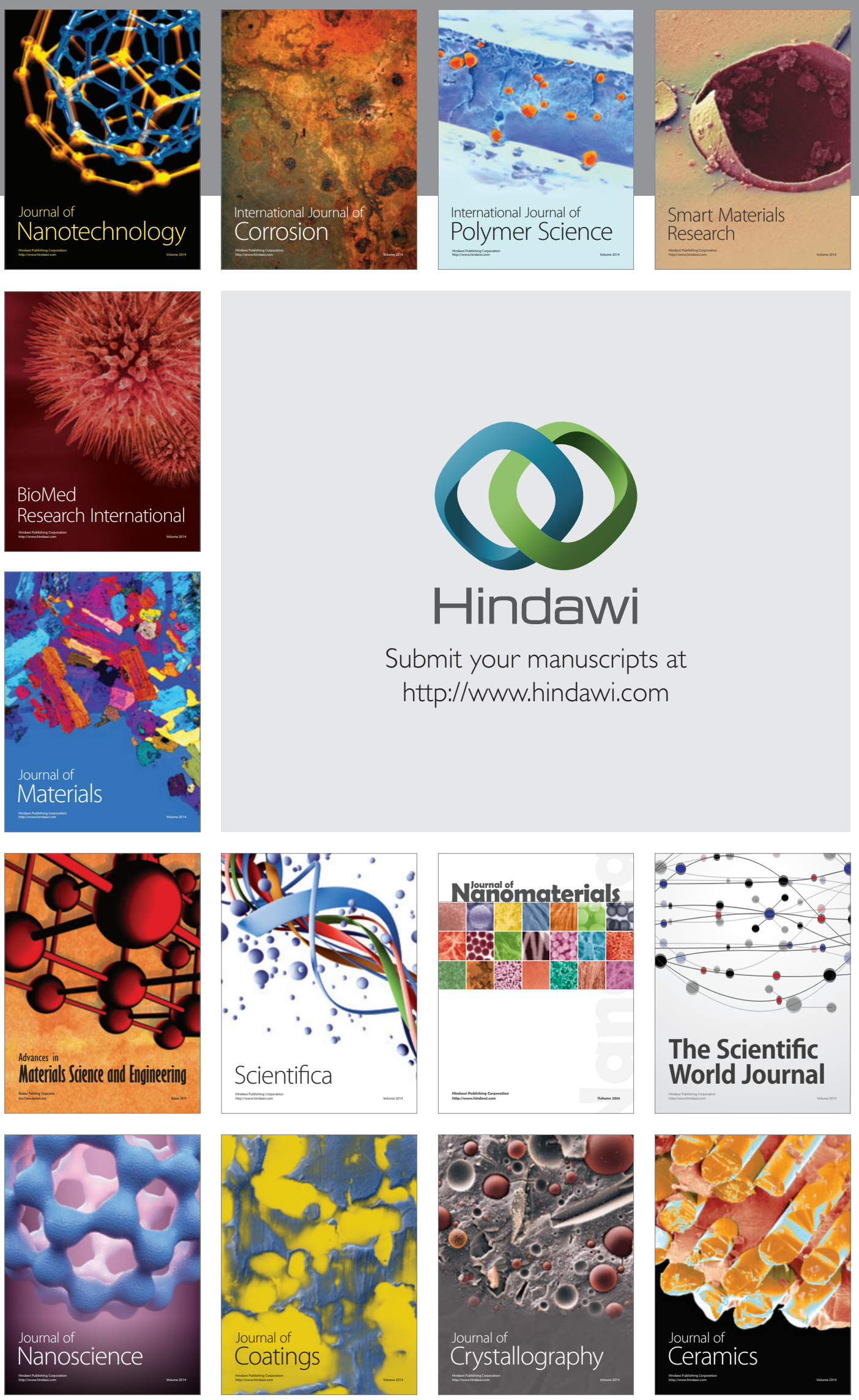

The Scientific World Journal

Submit your manuscripts at

http://www.hindawi.com

\section{World Journal}

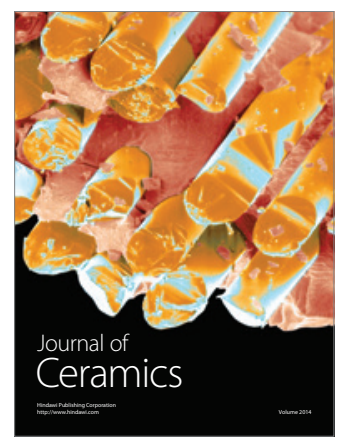

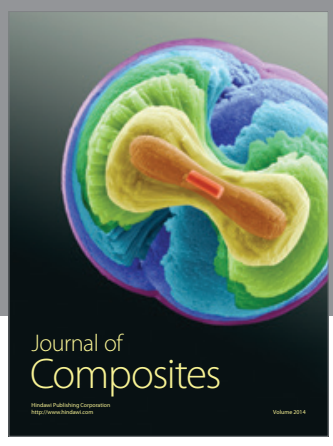
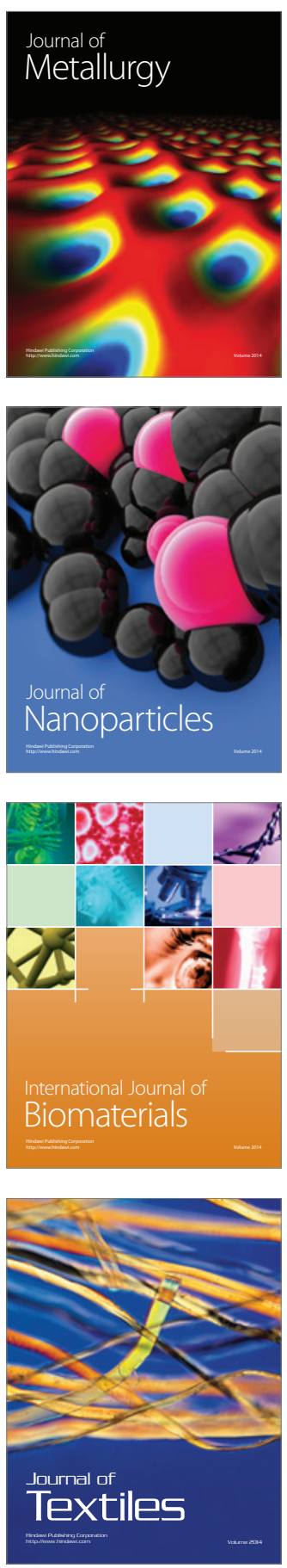